\title{
Experimental Investigation of Passive Infrared Ice Detection for Helicopter Applications
}

\author{
Adam Dershowitz and R. John Hansman, Jr. * \\ Department of Aeronautics and Astronautics \\ Massachusetts Institute of Technology \\ Cambridge, Massachusetts U.S.A
}

\begin{abstract}
A technique is proposed to remotely detect rotor icing on helicopters. Using passive infrared (IR) thermometry it is possible to detect the warming caused by latent heat released as supercooled water freezes. During icing, the ice accretion region on the blade leading edge will be warmer than the uniced trailing edge resulting in a chordwise temperanure profile characteristic of icing. Preliminary tests were conducted on a static model in the NASA Icing Research Tunnel for a variety of wet (glaze) and dry (rime) ice conditions. The characteristic chordwise temperature profiles were observed with an $\mathbb{R}$ thermal video system and confirmed with thermocouple measurements. A prototype detector system was built consisting of a single point $\mathbb{R}$ pyrometer, and experiments were run on a small scale rotor model. Again the characteristic chordwise temperature profiles were observed during icing, and the IR system was able to remotely detect icing. Based on the static and subscale rotor tests the passive IR technique is promising for rotor ice detection.
\end{abstract}

\section{Introduction}

The reliable measurement of ice accretion is an important requirement for helicopter all-weather operation. Rotor icing can present a significant hazard due to increased torque requirements, aerodynamic performance degradation, control problems and severe vibrations resulting from uneven ice shedding. Helicopter exposure to icing conditions has increased over the past decade due to the increase in routine instrument flight operations.

\footnotetext{
- Research Assistant

* Associate Professor, Associate Fellow AIAA
}

Copyright ( 1991 by M.I.T. Published by the American Institute of Aeronautics and Astronautics, Inc. with permission.
The two primary helicopter applications for ice detection are the monitoring of critical components for Caution and Warning alerts. and the management of ice protection systems. For Caution and Warning applications, ice accretion on critical components should be detected before a hazardous condition exists.

Because rotating components often experience a significantly different icing condition than the fuselage, visual evidence of ice accretion on non-rotating structures is not adequate for Caution and Warning applications. Indirect indications of icing such as torque rise or vibration typically emerge only after the hazardous condition exists. Ideally, the direct measurement of ice accretion on the rotating components would provide the earliest and most accurate measurement of potential icing hazards.

For helicopters equipped with ice protection systems. the management of these systems can be critical. The most common type of rotor protection is electrothermal deicing. These systems require significant amounts of electrical power so the blades are typically deiced in segments. Because there are no effective rotor ice detection systems it is necessary to overheat and continually cycle the electrothermal deicing systems to assure adequate ice protection. If effective ice detection were employed the deicing systems could be operated more efficiently and effectively.

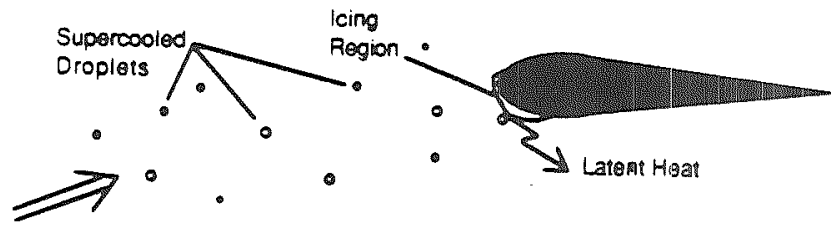

Fig. 1 Schematic representation of latem heal release during icing 


\section{Background}

\subsection{Existing Ice Detection Techniques}

The most common ice detectors currently employed for aviation applications are direct contact type devices. In contact type detectors, either a probe or surface mounted transducer senses the ice presence through a variety of physical mechanisms. These include resonant frequency shifts, optical blocking, heat capacity, electrical capacity, and ultrasonic thickness gauging. ${ }^{1}$

Contact type ice detectors have not been successfully utilized for direct measurement of rotor ice accretion due to the difficulties inherent in instrumenting the rotors. These include mounting restrictions imposed by structural limitations of the blade, transmission of information between the rotating and non-rotating frames, acceleration limitations of the sensors, and erosion problems. As a result. contact type detectors are typically mounted on the fuselage and the rotor conditions are inferred. ${ }^{2}$ These techniques have had limited success because of the complex dependence of the icing process on temperature, liquid water content and velocity, which vary significantly between the fuselage, and rotor as well as along the blade span itself.

\subsection{Remote Monitoring of Rotating Blades}

Remote sensing offers significant advantages for monitoring rotating blades. If ice accretion can be remotely detected by sensors mounted in the fuselage, then a direct measurement of rotor ice accretion can be accomplished without the difficulties identified above. Several potential techniques have been investigated for remote ice cletection including; high speed video, and active microwave. The technique which has emerged as the most promising is passive infrared.

\section{Passive Infrared Ice Detection}

\subsection{Theory of Operation}

The passive $\mathbb{R}$ technique detects ice accretion through remote $\mathbb{R}$ thermometry of the icing surface. When ice accretes on an airfoil or rotor, the region where the accretion occurs becomes warmer than the surrounding surface due to release of the latent heat of fusion as the impinging supercooled water droplets freeze. This process is shown schematically in Fig.1. It should be noted that the ice accretion is typically limited to a small region near the leading edge, and that much of the rotor surface will remain clear of ice. These uniced areas will have surface temperatures at or near the ambient temperature which will always be below freezing in icing conditions.
As a result of the thermodynamic processes described above, the rotors will exhibit a characteristic chordwise surface temperature profile when in icing conditions. Schematic temperature profiles are shown in Fig. 2 for wet and dry icing conditions. Prior to icing, the rotors will equilibrate to some temperature slightly warmer than the static air temperature due to kinetic heating. During icing, the temperature will increase in the accretion region as indicated in Fig. 2. For wet (glaze) ice accretions, the wet stagnation region will remain at $0^{\circ} \mathrm{C}$ while for dry (rime) accretions the temperature will reach a peak in the stagnation region at some temperature below freezing.

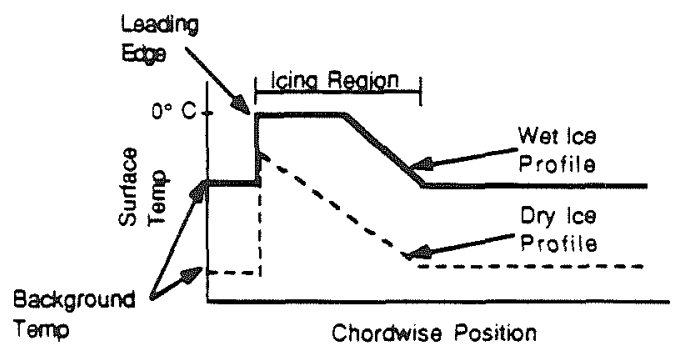

Fig. 2. Schematic chordwise temperature profiles for wet and dry icing conditions

In the proposed technique, shown in Fig. 3, the rotor surface temperature would be measured by an infrared pyrometer mounted on the fuselage which scans the blade in the chordwise direction as it passes overhead. The aim point of such a detector could be varied between span wise positions to give full coverage of the blade. Infrared pyrometers are commonly used to remotely measure surface temperature through thermally emitted black body radiation in the IR spectrum.

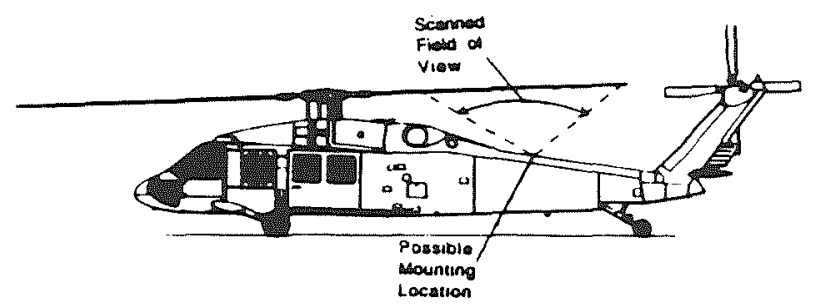

Fig. 3. Possible helicopter mounting scheme for a passive infrared ice detector

Passive $\mathbb{R}$ video thermography has been used for several years in the U.S. and France as a diagnostic tool for validation of ice accretion modeling codes. 3,4 Synchronized $\mathbb{R}$ video images have also been used to monitor rotating components in flight as part of the Advanced Turboprop development effort. ${ }^{5}$ Due to uncertainty in surface emissivity, attenuation through the icing cloud and thermal drift of the detectors it is 
sometimes difficult to accurately measure absolute temperature, however relative temperature resolution of $0.2^{\circ} \mathrm{C}$ is achievable. This is considered adequate for ice detection where only the relative temperature profile between the leading and trailing edge regions is required.

The passive IR system also has the potential to be used to monitor the operation of thermal deicing systems. Once ice sheds, the relatively hot blade surface will be exposed, resulting in an identifiable thermal signature.

\subsection{Static Tests}

\subsubsection{Experimental Setup for Static Tests}

In order to evaluate the feasibility of the passive $\mathbb{R}$ ice detection concept, a series of static tests were conducted in the NASA Icing Research Tunnel (IRT). These preliminary tests were conducted on a non-rotating $6 \mathrm{ft}$. chord airfoil model with a $25^{\circ}$ sweep which could be varied between $\pm 20^{\circ}$ angle of attack. The model was instrumented with thermocouples and electrothermal heaters in the leading edge region.

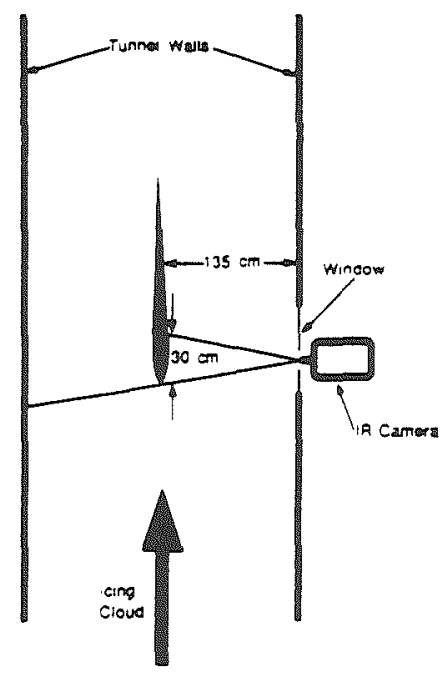

Fig. 4. Schematic of IRT setup

Infrared diagnostics were provided by a Hughes Probeye thermal imaging system which uses 6 Indium Antimonide (InSb) detectors and a spinning mirror to scan both horizontally and vertically. This imaging system, while somewhat more complex than required for an ice detection system, employs $\mathbb{R}$ detectors very similar to those proposed for use in the passive system. These detectors, when cryogenically cooled, are sensitive in wavelengths from 2.0 to 5.6 microns. In the imaging system the output of the detectors was fed into a processor that developed thermal video images and chordwise temperature profiles. The data was stored on videotape. In the experimental set up, shown in Fig. 4 , the IR camera was mounted outside of the tunnel and viewed the leading $30 \mathrm{~cm}$ of the airfoil through a hole in the tunnel window.

Experiments were run over a wide range of icing conditions, with airspeeds from $208 \mathrm{mph}(93 \mathrm{~m} / \mathrm{s})$ to $129 \mathrm{mph}(58 \mathrm{~m} / \mathrm{s})$ temperatures from $-17^{\circ} \mathrm{C}\left(2.4^{\circ} \mathrm{F}\right)$ to $-3^{\circ} \mathrm{C}\left(26^{\circ} \mathrm{F}\right)$ and liquid water content (LWC) from 0.53 $\mathrm{g} / \mathrm{m}^{3}$ to $1.96 \mathrm{~g} / \mathrm{m}^{3}$. For each experimental run the airfoil was first cleared of any ice. The airspeed and temperature of the wind tunnel was stabilized and the spray was then turned on for a predetermined time span. typically 1 to 3 minutes. In some cases the spray was cycled on a second time, for 30 seconds, without deicing first. This second cycle allowed verification of the ability of the technique to detect ice accretion over an existing ice layer.

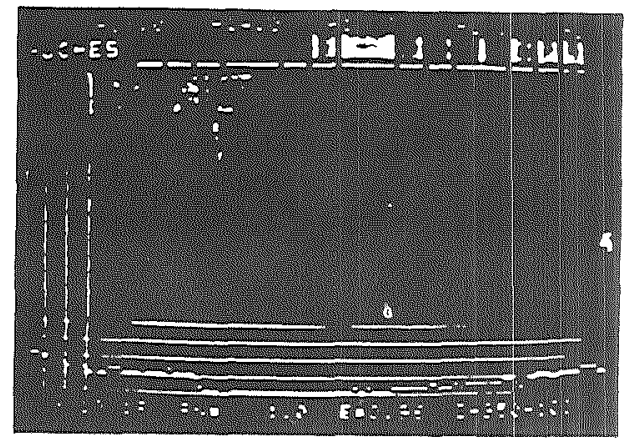

IRT ICING CLOUD OFF

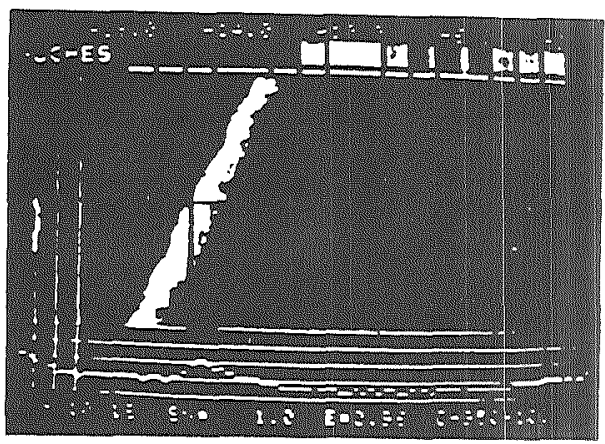

IRT ICING CLOUD ON

(MOTE WARMING OF LEADING EDGE)

Fig. 5. IR video outpur of model lower surfice $\left(\mathrm{T}=-11^{\circ} \mathrm{C}, \mathrm{V}=92 \mathrm{~m} / \mathrm{s}\right.$ $\left.\mathrm{LW} C=0.17 \mathrm{~g} / \mathrm{m}^{3}\right)$

\subsubsection{Static Test Results}

A typical $\mathbb{R}$ video image is presented in Fig. 5 for the swept airfoil at a tunnel temperanre of $-11^{\circ} \mathrm{C}$, a LWC of $0.17 \mathrm{~g} / \mathrm{m}^{3}$, with a mean volumetric diameter (MVD) of approximately 15 microns, an angle of attack 
of $4^{\circ}$, and a free stream velocity of $92 \mathrm{~m} / \mathrm{sec}$. Note that the chordwise temperature profile is shown across the bottom of the image. With the spray off, the airfoil surface temperature is uniform at approximately the tunnel temperature. When the spray is turned on, the increase in leading edge surface temperature resulting from the latent heat release is clearly visible. After the spray was tumed off, the leading edge would slowly cool as the remaining liquid water on the surface froze.

The $\mathbb{R}$, and themocouple measured chordwise temperature profiles for typical wet (glaze) ice conditions are presented in Fig. 6 . In this case the tunnel temperature was $-5^{\circ} \mathrm{C}$, the LWC was $1.95 \mathrm{~g} / \mathrm{m}^{3}$, with a MVD of 20 microns, the angle of attack was $10^{\circ}$, and the free stream velocity was $59 \mathrm{~m} / \mathrm{s}$. With the spray off, the airfoil had a uniform indicated temperature. The warmer temperature observed upstream of the stagnation point is an image of the wam tunnel wall behind the airfoil. When the spray was turned on, the expected surface temperature profile for wet growth was observed. The leading $8 \mathrm{~cm}$ of the airfoil indicated a surface temperature of $0^{\circ} \mathrm{C}$ indicating wet ice growth. Aft of the wet region, the surface temperature dropped to the uniced value. The $\mathbb{R}$ measurements were consistent with the thermocouple readings. The LEWICE ice accretion code was nun to simulate ice growth at these same conditions. The LEWICE predicted surface temperatures, as shown in

Fig 7 , are consistent with those measured with the
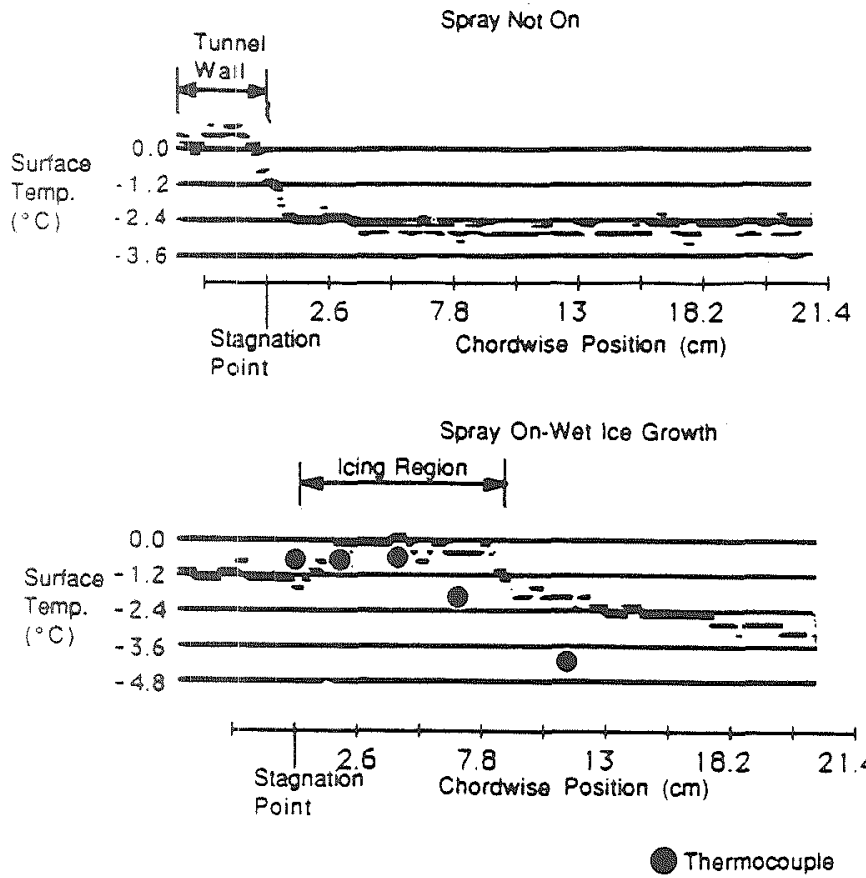

Fig. 6. Chordwise temperature profiles for wet (glaze) ice conditions $\left(T=-5^{\circ} \mathrm{C}\right.$, $\mathbb{V}=59 \mathrm{~m} / \mathrm{s}, \quad L W C=1.95 \mathrm{~g} / \mathrm{m}^{3}$ )
IR system. When the spray was turned off the surface temperature again became uniform as the surface water froze. When the spray was cycled on, the characteristic wet ice temperarure profile was again observed.

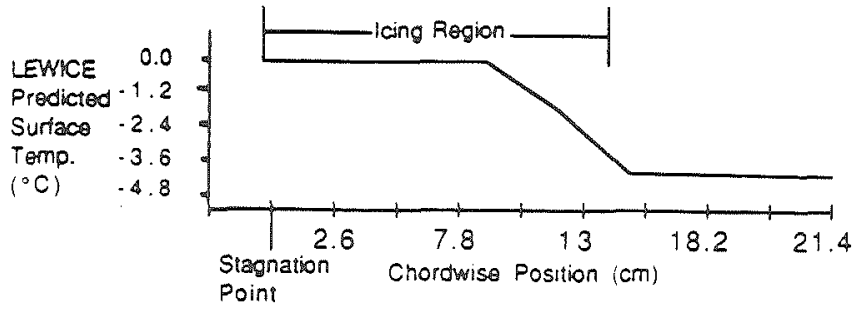

Fig. 7. LEWICE predicted temperature profile for wet (glaze) ice conditions ( $T=$ $\left.5^{\circ} \mathrm{C}, \mathbb{V}=59 \mathrm{~m} / \mathrm{s}, \quad \mathbb{W} C=1.95 \mathrm{~g} / \mathrm{m}^{3}\right)$.

The IR measured temperature profiles for a dry (rime) ice condition also show the expected temperature profile. An example is presented in Fig. 8. In this case the tunnel temperature was $-17^{\circ} \mathrm{C}$, the LWC was 0.17 $\mathrm{g} / \mathrm{m}^{3}$, with a MVD of approximately 15 microns, the free stream velocity was $92 \mathrm{~m} / \mathrm{s}$ and the angle of attack was $4.1^{\circ}$. With the spray off, the airfoil had a uniform indicated temperature. When the spray was turned on, the surface temperature was seen to peak at the stagnation point. This curve is characteristic of dry (rime) growth where the surface temperature reflects the local collection efficiency (i.e. increased impingement causes increased icing and increased heating). The stagnation point has the largest collection efficiency and consequently the greatest latent heat release. When the spray was turned off the temperature quickly dropped to the preicing value. The characteristic rime ice profile again appeared when the spray was cycled on.

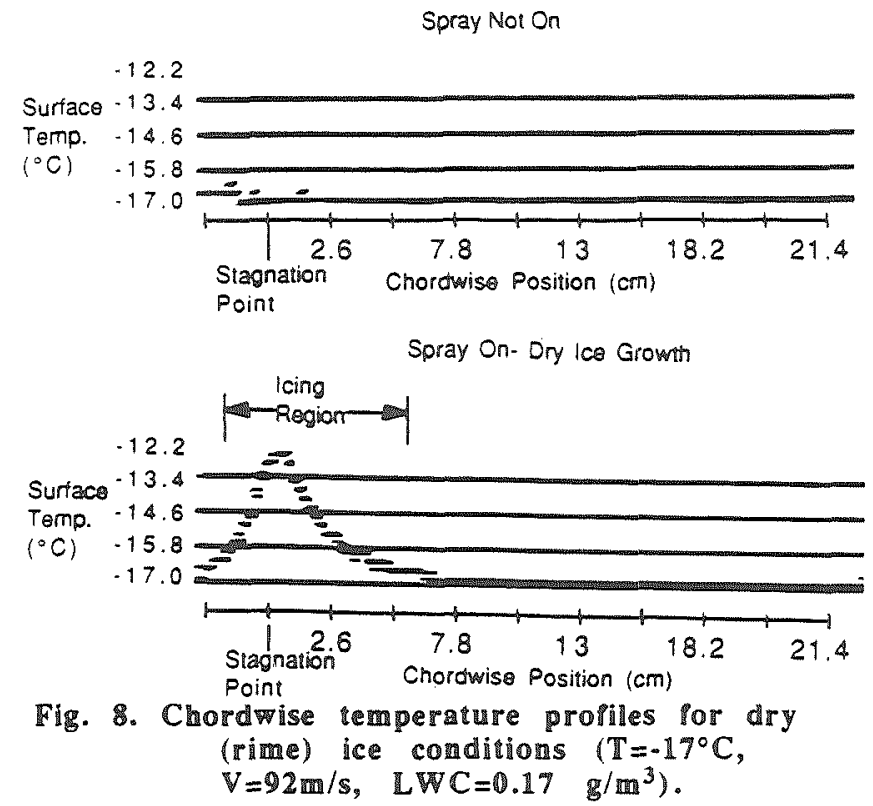




\subsection{Rotor Tests}

\subsubsection{Infrared Ice Detector Design}

In order to evaluate the $\mathbb{R}$ ice detection technique on rotating systems a prototype detector, suitable for both flight and ground tests, was developed. This ice detector, shown in Fig. 9, is essentially a point infrared pyrometer. It was built around a $\mathrm{HgCdTe}$ (Mercury Cadmium Telluride) infrared detector. This detector was chosen as it offers high sensitivity in the range of $2-5$ microns, using only thermoelectric cooling. Other detector types were considered, as they offer higher sensitivity, or operate at longer wavelengths. However they require cryogenic cooling, which would not be practical for flight operations. This detector uses a four stage thermoelectric cooler, with an automatic controller, to keep the temperature of the detector at $-73^{\circ} \mathrm{C}$. A gel cell battery was used to provide the bias for the detector at $2.6 \mathrm{~V}$.

The HgCdTe detector is positioned at the focus of a single Calcium Fluoride $\left(\mathrm{CaF}_{2}\right)$ lens. The simple biconvex lens had a $10 \mathrm{~cm}$ focal length. Calcium Fluoride was selected as it has high transmissivity in the necessary $\mathbb{R}$ band and is not overly sensitive to thermal shock, or water degradation. Concentric aluminum tubes were used, with a Teflon sleeve, to allow the length of the pyrometer to be adjusted giving a focus for a target distance from $15 \mathrm{~cm}$ to infinity. This range allows the prototype to be used on a small test rotor or in full scale flight tests. This lens gave the detector a target spot size of $0.18 \mathrm{~cm}$ diameter at 56 $\mathrm{cm}$ as used in the tests, and a spot size of $1 \mathrm{~cm}$ diameter at $3 \mathrm{~m}$, typical of a helicopter application. In order to prevent icing or fogging of the lens small gas jets were set up to spray dry nitrogen across the lens.

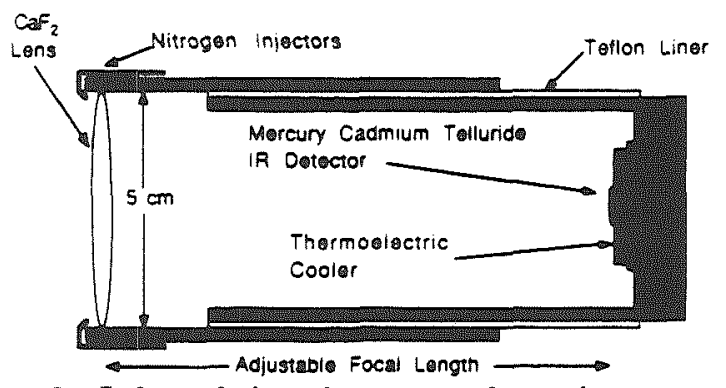

Fig. 9. Infrared ice detector schematic

The signal from the pyrometer itself was processed as shown in Fig. 10. It was first fed into a high gain, low noise amplifier. The amplifier was $\mathrm{AC}$ coupled to prevent saturation. This had the effect of amplifying only short term temperature changes. The signal was sent into a digital oscilloscope, and stored for post processing if required.

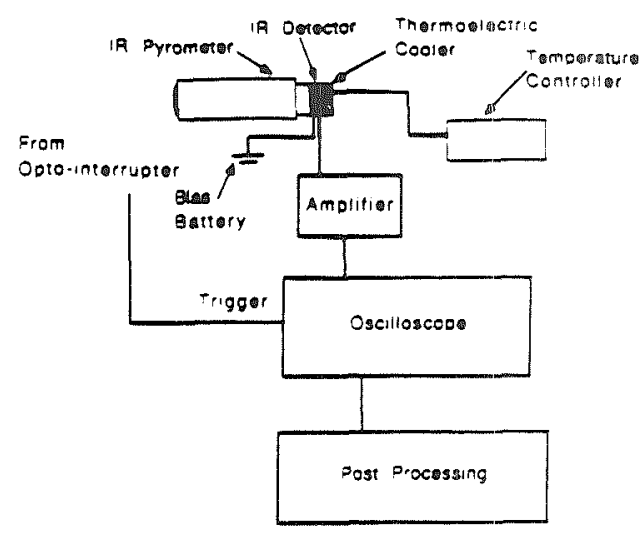

Fig. 10. Ice detector sigmal processing path

\subsubsection{Test Rig For Rotating Tests}

In order to test the prototype ice detector, a test rig was constructed. It consisted of a single blade counterbalanced rotor with a $22 \mathrm{~cm}$ span and a $2 \mathrm{~cm}$ chord, built of aluminum. schematically shown in Fig. 11. The small rotor was chosen to allowed the entire rig to be placed in a lab freezer. This system was able to run over a wide range of rotation speeds, from $0 \mathrm{~Hz}$ to $40 \mathrm{~Hz}$. The tests were nominally run at $22 \mathrm{~Hz}$ which allowed good ice formation, at reasonable rotor Reynolds numbers. The blade passed through the field of view of the pyrometer at an angular speed typical of a tail rotor. which is several times faster than that of a main rotor. This test therefore was conservative in that significantly faster detector dynamics were required than would be necessary for main rotor use. The angle of attack was adjustable over a range of positive and negative values. An opto-internupter was set up across the blade to measure rotation rate and to provide trigger pulses for tracking the blade.

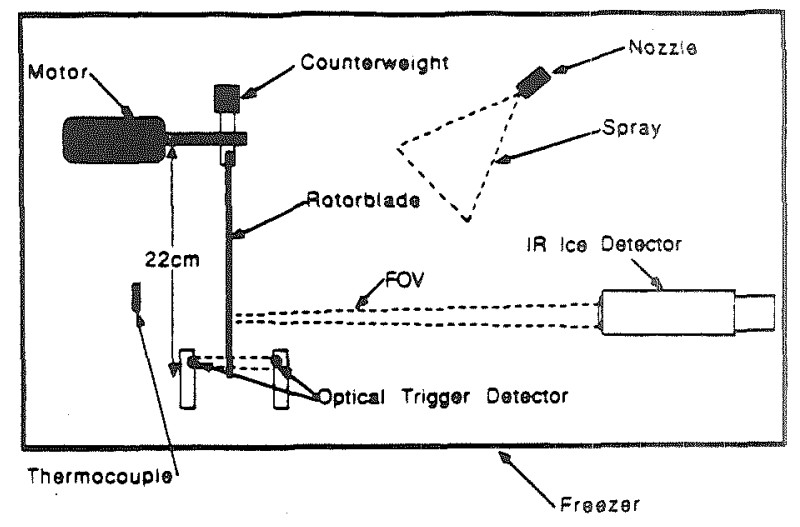

Fig. 11. Rotor test rig 
The rotor and ice detector were both mounted in a freezer which had a minimum temperature of $-23^{\circ} \mathrm{C}$. The lens was $56 \mathrm{~cm}$ from the rotor plane. The ice detector was aimed at the $13.5 \mathrm{~cm}$ span position of the rotor, and focused to provided the sharpest signal possible. Because of the exploratory nature of the tests, an uncalibrated water spray was considered adequate. A simple spray system with an estimated LWC of 0.9 $\mathrm{g} / \mathrm{m}^{3}$ at the rotor was used. The freezer temperature was measured using a thermocouple.

\subsubsection{Experimental Procedure}

For a trpical experimental run the blade rotation rate and freezer temperature were allowed to stabilize. The temperature and rotation rate were recorded. An uniced temperature profile was then recorded. Water at $0^{\circ} \mathrm{C}$ was then sprayed for $10 \mathrm{sec}$ and a temperature profille during icing was recorded. Several profiles were recorded after the icing event while the blade temperature profile was returning to equilibrium. Again the temperature and rotation rate were recorded. Finally the blade was deiced and the cycle was repeated. These runs were done over a range of temperatures from $-20^{\circ} \mathrm{C}$ to $60^{\circ} \mathrm{C}$, and at several different angles of attack. During icing the rotation rate would drop slightly due to the increased drag from the ice, and the temperature would rise from opening the freezer, which was necessary to initiate the spray.

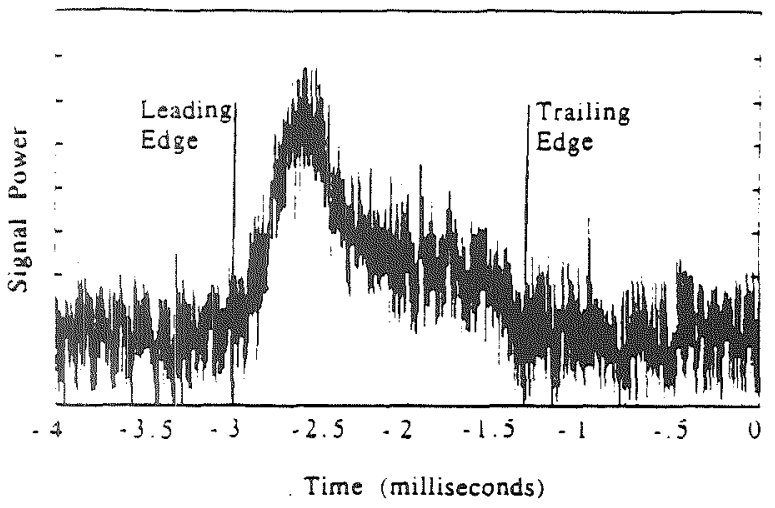

Fig. 12a. Unfutered IR temperature profile

\subsubsection{Rotor Results}

A typical unfiltered signal from the pyrometer is shown in Fig. $12 \mathrm{a}$ at $-6.8^{\circ} \mathrm{C}, 22 \mathrm{~Hz}$ and $0^{\circ}$ angle of attack. The signal is shown in arbitrary units because only the temperature profile is of interest and the signal scales with amplifier gain, DC offset, and detector bias voltage. Because the signals contained a component of high frequency noise, they were digitally low pass filtered at $10 \mathrm{kHz}$ resulting in signals as shown in Fig. 12b. As expected there was significant heating in the leading edge region, where there was icing occurring, while the rest of the blade remained at a relatively constant temperature. This is the same characteristic profile that was measured in the static tests. Before the spray began, the blade and the back wall of the freezer were at thermal equilibrium as indicated by the relatively flat line.

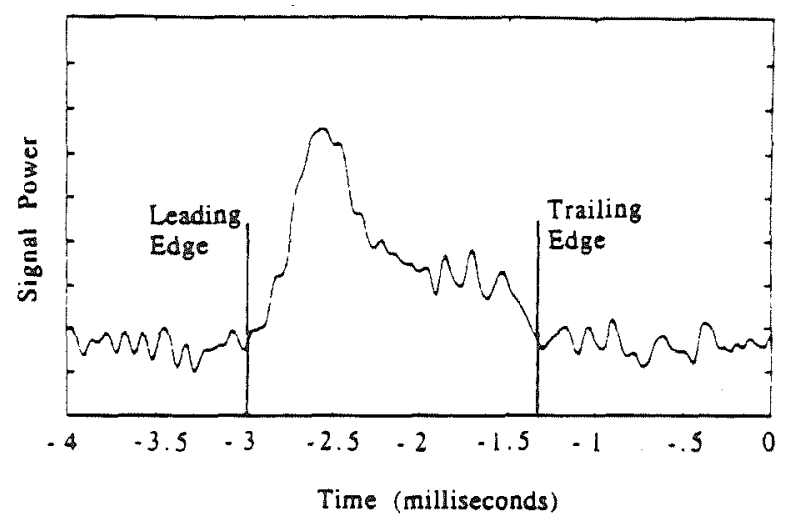

Fig. 12b. IR profile filtered at $10 \mathrm{kHz}$

Figs. 13 through 16 show the effect of ambient temperature on the signal. For all of these cases the rotor started at $22 \mathrm{~Hz}$ with $0^{\circ}$ angle of attack, and the spray $L W C$ is $0.9 \mathrm{~g} / \mathrm{m}^{3}$. During very cold conditions, such as Fig. $13\left(-15^{\circ} \mathrm{C}\right)$ where there was a large temperature difference between ambient and freezing, there was a correspondingly large temperature change in the icing (leading edge) region of the blade. This resulted in the strong temperature profile shown in Fig. 13. Fig. $14\left(-6.8^{\circ} \mathrm{C}\right)$ show a signal typical of glaze ice, where the icing profile is clearly visible. Fig. $15\left(-3^{\circ}\right.$ C) shows a case just below freezing, where there was minimal glaze ice. Because the ambient temperature was close to $0^{\circ} \mathrm{C}$ the signal is small but clearly detectable. When the blade was stopped to be deiced there was only a small amount of ice present. A temperature profile taken at a temperature just above icing conditions is shown in Fig. 16. There was no signal indicative of icing, which is consistent with the observation that there was no ice accretion on the blade after the run.

In order to evaluate any changes in detectability with angle of attack, the angle of attack was varied over several runs. There was very little change in the temperature profile signal, although the higher angle of attack runs did include a slightly wider heating region, due to the increased size of the icing region. 
Spray Not On

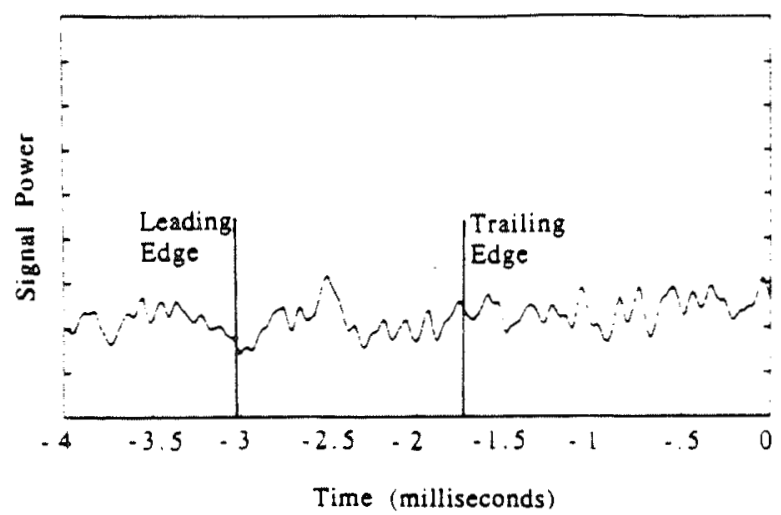

Spray On

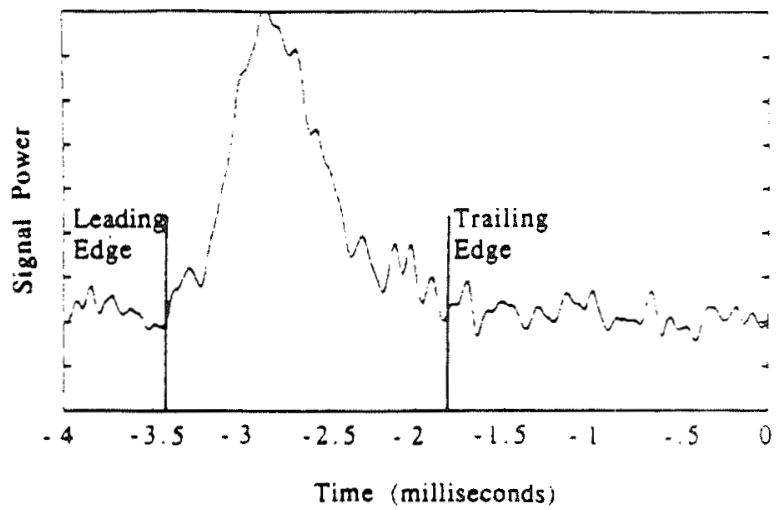

Fig. 13. IR Profiles at $\mathrm{T}=-15^{\circ} \mathrm{C}$ with and without water spray

Spray Not On

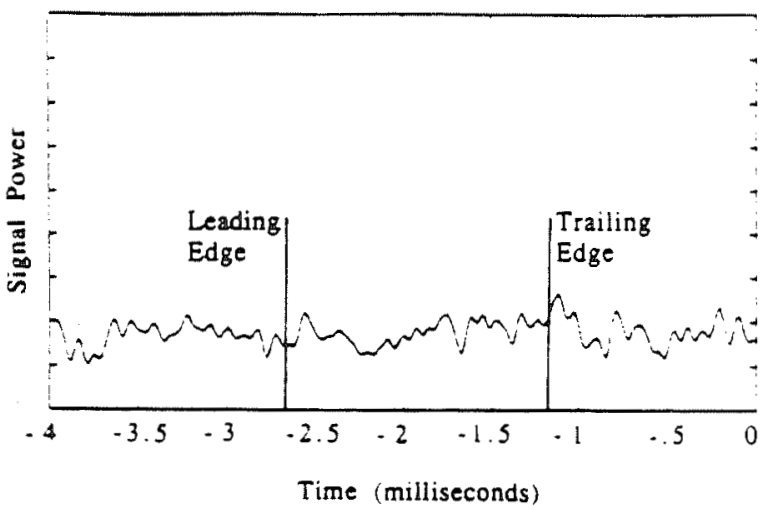

Spray On

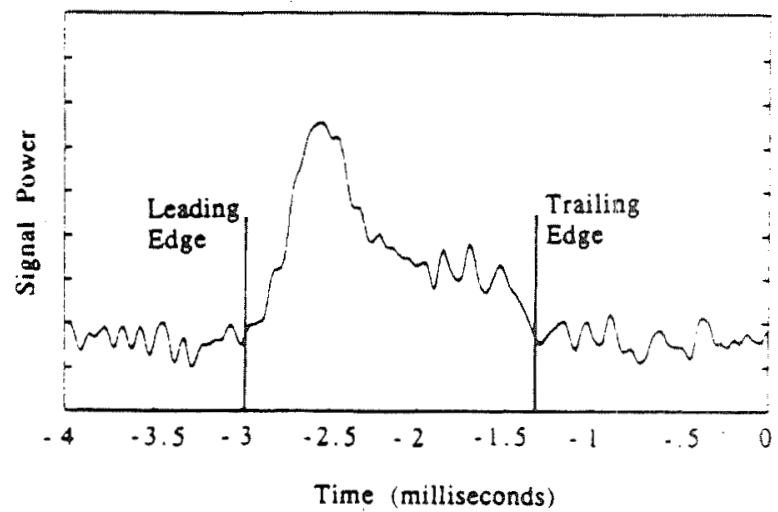

Fig. 14.IR Profiles at $\mathrm{T}=-6.8^{\circ} \mathrm{C}$ with and without water spray

Spray Not On

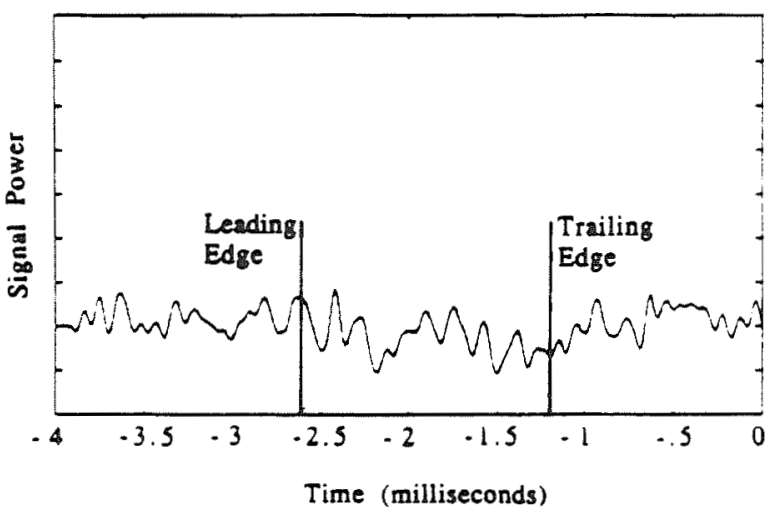

Spray On

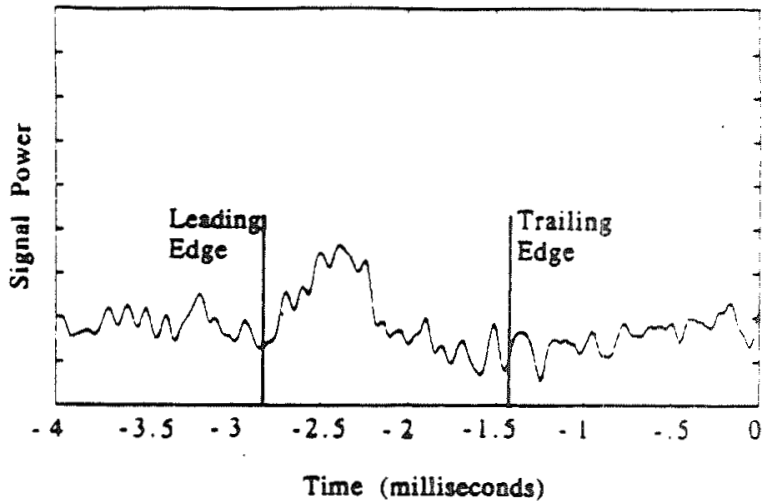

Fig. 15. IR Profiles at $\mathrm{T}=-3^{\circ} \mathrm{C}$ with and without water spray 

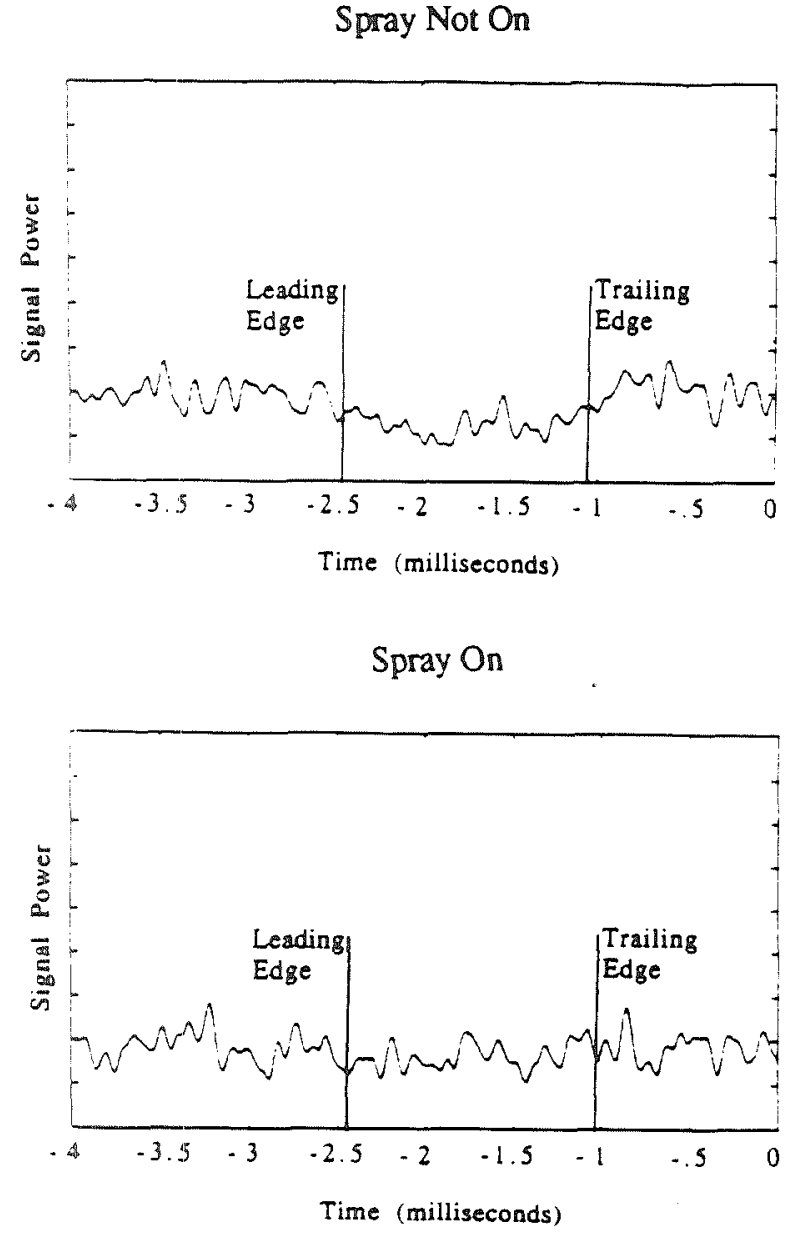

Fig. 16. IR Profiles at $\mathrm{T}=-0.4^{\circ} \mathrm{C}$ with and without water spray

\section{Implementation Issues}

While the above experiments indicate the potential of remote IR ice detection there are still several implementation issues to be considered. The rotor model did not include blade flapping or significant blade bending. These effects, in a helicopter application, will make it more difficult to track the blade location, and to keep it in focus. This may be addressed by use of a wide depth of field, or use of an auto focus system referenced to the blade leading edge.

Another issue to be considered is placement of the pyrometer on the helicopter. It will be necessary to mount the pyrometer so that it can view the blades, or possibly the tail rotor. Although small amounts of frost on the lens did not significantly degrade the signal in the rotor tests, it will be necessary to prevent the lens of the pyrometer from icing, frosting or becoming wet.
Signal processing is also an implementation issue, although it should be fairly straightforward. The signal must be amplified and synchronized with the rotor. It must be filtered, and then the profile compared to known icing conditions to determine the presence of ice. A simple leading edge to trailing edge temperature difference method may prove adequate. This data must be presented to the pilot in a useful format.

\section{Conclusion}

The results from preliminary IRT experiments, and the follow up rotor tests indicate that passive infrared ice detection can be used to remotely detect ice accretion on airfoils and rotors by measuring the characteristic chordwise temperature profiles which result from the release of latent heat during freezing. The technique has promise as a technique for remotely monitoring the icing of helicopter rotor blades. A prototype, suitable for flight testing, has been developed and successfully tested on a small scale rotor.

\section{Acknowledgements}

This work was supported by the National Aeronautics and Space Administration under grant NGC 3-927. The authors would like to thank the B.F. Goodrich Company and the Douglas Aircraft Company for their cooperation during the IRT tests and Professor Ken Dewitt and Alan Yaslick for providing thermocouple data.

\section{References}

1. Heinrich, A. Ross, R. Zumwalt, G., Provorse, J., and Padmanabhan, "Aircraft Icing Handbook - Vol. I", DOT/FAA/CT - 88/8-1, March 1988.

2. Corley-Byrne, P.L., "Helicopter Icing and It's Measurement", Presentation at SAE subcommittee meeting AC-9C - Aircraft Icing Technology, October 1986.

3. Hansman, R., Yamaguchi, K., Berkowitz, B., and Potapczuk, M., "Modelling of Surface Roughness Effects on Glaze Ice Accretion", AIAA-89-0734, AIAA 27th Aerospace Sciences Meeting, January 1989.

4. Henry, R. and Guffond, D., "Application de la Thermographie Infrarouge a l'Interpretation d'Essais dans une Soufflerie Givrante", Societe Francaise des Thermiciens, January 1989.

5. Skebe, S., "Synchronous Thermography", 3rd Japan-China joint conference on Fluid Machinery, April 1990 